\title{
Transdisciplinary methods of the future physical culture teacher's soft skills competencies formation
}

\author{
Vladislav Zhabakov*, Tatiana Zhabakova, Larisa Kravtsova \\ South-Ural State Humanitarian-Pedagogical University, 454080, Chelyabinsk, Russia
}

\begin{abstract}
The article substantiates the urgency of transdisciplinary methods of soft skills competencies formation. As a result of theoretical summarizing of psychological-pedagogical literature, concerning the problem of the research, we revealed attributive features of "soft skills competencies" notion: universality, situatedness, cooperativity, longitudness, directivity. As transdisciplinary methods of the future physical culture teacher's soft skills competencies formation the authors of the article use the methods of transdisciplinary consulting, transdisciplinary tutorship, methods of transdisciplinary supervision, "shadowing", "in-basket"; "secondment"; "buddying" methods modification. The forming experiment was held in natural conditions and was directed toward studying the effectiveness of competencies soft skills formation transdisciplinary methods. During the experimental work the authors formed CG (control group), EG-1(methods of transdisciplinary consulting, transdisciplinary tutorship); EG-2 (methods of transdisciplinary supervision); EG-3 ("shadowing", "in-basket"; "secondment"; "buddying" methods). For statistical results handling the authors used "SPSS v 17.0" software program, Fischer test $\varphi^{*}$. It was underlined that transdisciplinary methods of competencies soft skills introduction conditioned statistically significant changes in modified competencies concentration, priority, tension and support in the future physical culture teachers' notions in the experimental groups.
\end{abstract}

\section{Introduction}

In modern educational process the notion "competency" becomes a system forming factor of a higher educational establishment teacher's activity. That is why the central tendencies of students' high level of training provision at a pedagogical higher educational establishment becomes the orientation to competencies soft skills formation as a methodological "ideology" in training the future physical culture teachers. Firstly, soft skills competency become not only the indicators of success, but also the index of intellection divergence. It conditions the ability of a personality to function effectively in terms of modern pedagogical activity multitasking character. Secondly, soft skills competencies are able to provide transdisciplinary unity of training the future physical culture teachers, providing not "teaching, but creative self-study" during professional self-development. Thirdly, soft skills competencies, oriented toward different cognitive resources development, determine the effectiveness of pedagogical communication. Thus, soft skills competencies formation among the future physical culture teachers helps not only to improve the quality of pedagogical education [1], but also increasing practice-oriented aspects of teaching, fill the content of education with innovative transdisciplinary forms and methods of training the future teachers.

\section{Materials and Methods}

At the first stage of the research, using the methods of comparative analysis, classifications, summarizing, analysis and synthesis, we defined attributive features of "soft skills competencies" notion:

1) Universality: soft skills competencies are important and necessary for a successful professional and life self-determination of people irrespective of professional sphere or profession. Universal competencies in federal state educational standards of the third generation $(3++)$ are possible to consider as contextual synonyms of soft skills competencies, as it is supposed that universal competencies should be formed in students as a result of mastering educational programs of different stages of education [2].

2) Situatedness: soft skills competencies determine the level of personal effectiveness in a definite situation, being contextual synonyms of flexibility, adaptivity, divergence, ability to realize multitasking.

3) Cooperativity: soft skills competencies include the lines of a personality communications, condition the effectiveness of social interaction, including the spectrum of social-psychological qualities of a personality.

\footnotetext{
${ }^{*}$ Corresponding author: gabakovvu@ yandex.ru
} 
4) Longitudness: soft skills are considered as the ways of actions, "given" through additional education, reflexion of "trials and errors" in a personal life experience, systematically used for professional improvement and personal self-development.

5) Directivity: in the concept of A.E. Tsymbalyuk, V.O. Vinogradova [3] soft skills competencies are characterized through such vectors, as directed toward a person himself, toward other people, toward generalprofessional objectives solution.

The aim of training a future physical culture teacher in the concept of V.E. Zhabakova is determined by transdisciplinary worldview position. It the priority is given to objective and intersubjective scientific knowledge [4]. Such kind of worldview position helps to consider the process of the future physical culture teacher's soft skills competencies formation as a purposeful pedagogical process, directed toward the conditions creation for mastering the ways of actions connected with an effective professional problems solution in terms of pedagogically oriented transdisciplinary picture of the world. That is why at the second stage of the research we defined transdisciplinary methods of soft skills competencies formation of the future physical culture teacher.

The universal character of a future physical culture teacher's soft skills competencies, in our opinion, are formed by such methods as transdisciplinary consulting and transdisciplinary tutorship.

Transdisciplinary consulting we consider as a special kind of pedagogical consulting, directed toward consulting help realization in problems solution, connected with educational-cognitive activity and personal professional development in the context of transdisciplinary combination of the disciplines. Transdisciplinary consulting helps to solve both strategic objectives of the future physical culture teachers training, directed toward transdisciplinary competencies of teachers transformation, and tactical ones. They help to introduce transdisciplinary methods into the process of education. The ideas of transdisciplinary consulting in education are methodologically similar to the main items of transdisciplinary tutorship.

S.Yu. Lavrentev, D.A. Krylov [5] define the kinds of tutorship. It in our opinion, is possible to include into transdisciplinary methods of soft skills competencies formation of a future physical culture teacher:

- situational mentoring. A short-term consulting in order to stimulate soft skills competencies formation of a future physical culture teacher in the separate parts of educational process, for example, in terms of one lesson, physical exercise fulfillment and etc..

- supervisory mentoring. This kind of transdisciplinary tutorship is more effectively realized during pedagogical practice, when students and the heads of the practice discuss an optimal possible plan of actions, taking into consideration transdisciplinary combination of disciplines.

As one of the forms of transdisciplinary tutorship realization, during which cooperativity and longitudness of soft skills competencies effectively develop, we offer imitating modeling of professional pedagogical activity. It, on the one hand, helps to reproduce the context of problem objectives maximum close to "everyday" professional activity. And on the other hand, gives situations, which demand realization of the model of behavior and this way forming soft skills competencies of the future physical culture teacher.

During transdisciplinary supervision mostly the situatedness of soft skills competencies is demonstrated. Transdisciplinary supervision as a special kind of pedagogical supervision of the future physical culture teachers training presents transdisciplinary representations analysis of interactions between a personality and environment. An objective result of such interaction becomes the notions transformation concerning corporality as a psychological determinant [4] of the future physical culture teacher training. "Reflected corporality" becomes the core of supervision transdisciplinary, combining general and special; identity, accidental and regular; essence and phenomenon; reason and consequence; identity and contradiction; unity, interaction and resistance during supervision. The range of situation transdisciplinary elements are determined as the system of subjective and objective elements. They are combined in a subject's activity in a form of competence, emotional perception, autonomy, identity. Transdisciplinary supervision in this connection is presented as self-directed system. It is realized in transdisciplinary educational environment, sets contacts of the future physical culture teachers with this environment.

Soft skills competencies, directed toward a person himself, toward other people, toward general-professional objectives solution (according to the concept of A.E. Tsymbalyuk, V.O. Vinogradova) were formed by us during the following methods realization: «shadowing»; «in-basket»; «secondment»; «buddying». Teaching with "shadowing" method in the present research means transdisciplinary modification of standardized observation and selfobservation methods. At the first stage of "shadowing" a plan of observation and self-observation is created over the actions of teachers, students, own ways of actions on the subjects included into "the core of transdisciplinarity". Moreover, a student has to record all not clear moments. After such practice pedagogical supervision with the future physical culture teachers is held. The aim of the supervision is to study self-assessment of soft skills formation level. Teaching with "in-basket" method, based on the ways of actions development in terms of transdisciplinary information analysis, helps to estimate the ability of the future physical culture teachers to analyze, systematize and select, classify information, text structuring, the ability to search for the solutions on the basis of the offered information, contradictions in information revelation. The structure of tasks according to "in-basket" method includes the tasks for information localization, transdisciplinary interpretation of information, the ways of actions reflection. "Secondment" [6] as the method of transdisciplinary teaching provides students rotation in terms of lessons organization in the groups of sportsmanship improvement. We think that the result of students "mixing" 
would be a creative development of professional soft skills competencies, pedagogical physical-sports development, communication effectiveness increase.

Soft skills competencies, in our opinion, have special psychological content, apart from professional orientation considerably influence personal essences, systems of relations. That is why during the period of adaptation to studying at a higher educational establishment the most effective method of soft skills competencies formation is "buddying". The essence of the method is in the fact that a student has a "buddy", a partner. His aim is to give constant feedback concerning the actions and solutions of the person, whom he directs. Buddying differs from supervision or coaching by status and psychological "equality" of the participants $[7,8]$. The main aim of buddying is support and feedback. Buddy or "a friend" gives "the zone of real and possible", but he doesn't estimate. It creates the conditions for effective adaptation, self-test in quasiprofessional acivity during pedagogical practice, using situatedness of soft skills competencies in the definite activity.

Transdisciplinary methods of soft skills competencies formation of a future physical culture teacher are combined by horizontal and vertical transdisciplinary transformation of disciplines, integral transdisciplinary semantic notions, the sequence of methods use determination at all levels of training.

\section{Results and Discussion}

The forming experiment was held in natural conditions and was directed toward studying the effectiveness of transdisciplinary methods of competencies soft skills formation. During the experimental work the authors formed CG (control group), EG-1(methods of transdisciplinary consulting, transdisciplinary tutorship); EG-2 (methods of transdisciplinary supervision); EG-3 ("shadowing", "in-basket"; "secondment"; "buddying" methods).

For qualitative estimation of soft skills competencies formation level we used a modified questionnaire by B.G. Baydenko [8], which defines the importance of competencies for the respondent (concentration, low priority, overtension, support) and the level of achievement as the criteria of competencies formation.

After the forming experiment we see qualitative change of indices according to importance of competencies criterion for the respondents of EG-1, EG-2, EG-3. In EG-1 there is considerable increase according to "support" criterion - 40,7\%. The respondents mention the importance and high level of achievements during soft skills competencies. It should be noted that qualitative changes, which are seen in EG-1, EG-2, EG-3 according to "achievement level" criterion. Self- assessment of soft skills competencies achievement changed in EG-1 by 18,5\%, in EG-2- 32\%, in EG-3-40,7\%. As a result of studying soft skills competencies formation we see qualitative changes in the experimental groups. In EG-1, EG-2 we revealed statistically valid changes according to "concentration" and "low priority" indices. We define the amount of respondents decrease. They mention "low priority" of soft skills competencies formation by $52 \%$ and "over-tension" criterion indices decrease by $56 \%$. In EG3 we also see statistically valid changes of soft skills self-assessment competencies formation. In CG we see changes, however, they can't be considered statistically valid.

For qualitative estimation of the respondents' answers we used content-analysis methods. They help to make the conclusion, that in experimental groups after experimental work modality of statements changed. In particular, we see frequency increase of semantic units use with the notion "subject-subjective positive perception of the teaching process" (mode 9), "aim achievement" (mode 6), "satisfaction with the process of studying" (mode 5). As a result of the empiric research we see statistically valid differences in semantic constructions use with the notion "timely perspective". In terms of error $(\rho \leq 0,01)$ we revealed the differences in description of timely perspective between CG and EG-1 ( $\varphi * e m p=3,35$, in case $\varphi * c r=1,64(\rho \leq 0,05)$ and $2,31(\rho \leq 0,01))$, in the notions of the future CG and EG-2 $\left(\varphi *\right.$ emp $=3,33$ in case $\varphi^{*} \mathrm{cr}=1,64(\rho \leq 0,05)$ and 2,31 $\left.(\rho \leq 0,01)\right)$, CG and EG-3 $\left(\varphi * e m p=5,1\right.$ in case $\varphi^{*} \mathrm{cr}=$ $1,64(\rho \leq 0,05)$ and $2,31(\rho \leq 0,01)$.

Thus, it should be said that the process of soft skills competencies formation influences greatly the notions of respondents concerning the process of studying. Experimental groups comparison shows that statistically valid differences in the notions of the respondents between EG-1 and EG-2, EG-3 in case of error $(\rho \leq 0,05)$. The complex of transdisciplinary methods of soft skills competencies formation demands further experimental research.

\section{Conclusions}

In our research work the notion soft skills competencies is considered through the prime of such attributive features, as universality, situatedness, cooperativity, longitudness, directivity. The process of soft skills competencies formation is considered as an integration of different research forms and methods, ioncluding such special and modified methods as transdisciplinary consulting, transdisciplinary tutorship, methods of transdisciplinary supervision, "shadowing", "in-basket"; "secondment"; "buddying" methods modification. During soft skills competencies formation we revealed essence and content of competencies complication in the notions of the experimental groups respondents. As a context, which would preserve the unity of educational sphere, "core of transdisciplinarity", in accordance with the concept by V.E. Zhabakov, we considered transdisciplinary worldview position. In this case the level of soft skills competencies formation, in particular the ability of a future physical culture teacher set and understand educational objective, the formation level of the actions with information, text ways actions in situation of imitating modeling, can serve the base for the process of competencies formation 
transformation into the form of subjectivity, as a qualitatively new peculiarity of a future physical culture teacher's personality (subject of activity and subject of relation with people around).

The article is prepared with the help of financial support of Federal State Budgetary Educational Establishment of Higher Education "Mordovian State Pedagogical Institute named after M.E. Evseev" according to the contract of scientific-research works realization №16-285 01.06.2020 the topic "Transdisciplinary model creation of estimating the quality of training the future physical culture teachers".

\section{References}

1. V. D. Shadrikov, Psychology of activity and a person's ability (Logos, Moscow ,1996)

2. T.A. Yarkova, I.I. Cherkasova, Bulletin of Tyumen State University. Humanitarian research works, 2(4), $222-231$ (2016)

3. A.E. Tsymbatyuk, V.O. Vinogradova, Yaroslavl Pedagogical Bulletin, 6(111), 120-127 (2019)

4. V.E. Zhabakov, T.V. Zhabakova, V.G. Makarenko, G.P. Konyakhina, Person. Sport. Medicine, 18, 98-103 (2018)

5. S.Yu Lavrentiev, D.A. Krylov, Mari State University bulletin, 13(2), 182-188 (2019), DOI: 10.30914/2072-6783-2019-13-2$182-188$

6. O.L. Chulanova, D.V. Veretelnik, Internet-journal "World of science", 4 (2014)

7. A.S. Kuznetsov, Z.M. Kuznetsova, Russian Journal of Physical Education and Sport, 14(4), 5-7 (2019)

8. V.I. Baydenko, Revealing the content of competencies of graduates as a necessary stage of new generation State Educational Standards of Higher Professional Education projection: methodical manual (Research center of problems of quality of specialists training, Moscow, 2006) 